\title{
Self-Enhanced Electrochemiluminescence Nanorods of
}

\section{Tris(bipyridine) Ruthenium (II) Derivative and Its Sensing}

\section{Application for detection of $\mathrm{N}$-acetyl- $\beta$-D-glucosaminidase}

\author{
Haijun Wang, Yali Yuan, Ying Zhuo, Yaqin Chai*, Ruo Yuan*
}

Key Laboratory of Luminescent and Real-Time Analytical Chemistry, Ministry of Education, College of Chemistry and Chemical Engineering, Southwest University, Chongqing 400715, People's Republic of China

* Corresponding author: Tel.: +86-23-68252277; Fax: +86-23-68253172.

E-mail address: yqchai@swu.edu.cn, yuanruo@swu.edu.cn 


\section{Table of Contents}

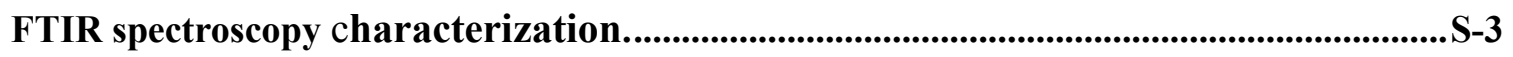

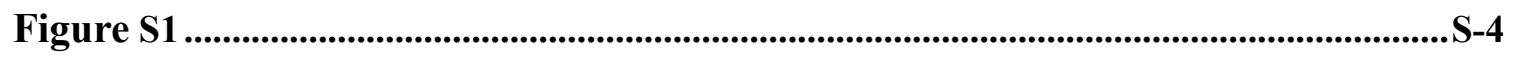

UV-vis absorption spectroscopy characterization ............... S-Error! Bookmark not defined.

Figure S2 ...................................................................................... S-Error! Bookmark not defined. 


\section{Fourier transform infrared spectroscopy characterization of different complexs}

$\mathrm{Ru}(\mathrm{bpy})_{2}(\mathrm{mcbpy})^{2+}$-TAPA was characterized by Fourier transform infrared (FTIR) spectroscopy. The FTIR spectra of Ru(bpy $)_{2}(\mathrm{mcbpy})^{2+}$, TAPA, and Ru(bpy $)_{2}(\mathrm{mcbpy})^{2+}-\mathrm{TAPA}$ were shown in Figure $\mathrm{S} 1$. The $\mathrm{Ru}(\mathrm{bpy})_{2}(\mathrm{mcbpy})^{2+}$ showed typical absorption peaks at 774.2 , 1462.4 and $1617.5 \mathrm{~cm}^{-1}$ (curve a), which corresponded to bipyridyl cyclic organic structures. Simultaneously, $\mathrm{Ru}(\mathrm{bpy})_{2}(\mathrm{mcbpy})^{2+}$ had absorption peaks at 1708.3 and $3413.9 \mathrm{~cm}^{-1}$ due to the $\mathrm{C}=\mathrm{O}$ and the $\mathrm{O}-\mathrm{H}$ stretching vibration of the carboxylic acid groups, respectively. In the FTIR spectrum of TAPA (curve b), the peaks at $899.8,1600.74 \mathrm{~cm}^{-1}$ were assigned to $\mathrm{C}-\mathrm{N}$ and $\mathrm{N}-\mathrm{H}$ bending vibration of primary amine. The double peaks at 3283.4 and $3358.4 \mathrm{~cm}^{-1}$ were assigned to N-H stretching vibration of primary amine. After the formation of Ru(bpy $)_{2}(\text { mcbpy })^{2+}$-TAPA complex through amidation reaction, the characteristic peak of $\mathrm{C}=\mathrm{O}$ stretching vibration of amide bond appeared obviously at $1659.6 \mathrm{~cm}^{-1}$ (curve c). At the same time, some characteristic peaks of $\mathrm{Ru}(\mathrm{bpy})_{2}(\mathrm{mcbpy})^{2+}$ and TAPA were still retained in the spectrum of the $\mathrm{Ru}(\mathrm{bpy})_{2}(\mathrm{mcbpy})^{2+}$-TAPA complex, but had some shift owing to the change of molecular structure. For example, the characteristic peaks of bipyridyl cyclic shifted from 774.2, 1462.4 and $1617.5 \mathrm{~cm}^{-1}$ to $763.8,1445.5$ and $1575.8 \mathrm{~cm}^{-1}$. And the absorption peak for $\mathrm{C}-\mathrm{N}$ bending vibration in primary amine shifted from $899.8 \mathrm{~cm}^{-1}$ to $883.7 \mathrm{~cm}^{-1}$. In addition, there was a broad peak between 3211.4 to $3398.4 \mathrm{~cm}^{-1}$, which might belong to the overlapping of $\mathrm{N}-\mathrm{H}$ stretching vibration of primary amine and $\mathrm{O}-\mathrm{H}$ stretching vibration of residual solvent. All the results above suggested the successful synthesis of Ru(bpy $)_{2}(\text { mcbpy })^{2+}$-TAPA complex. 


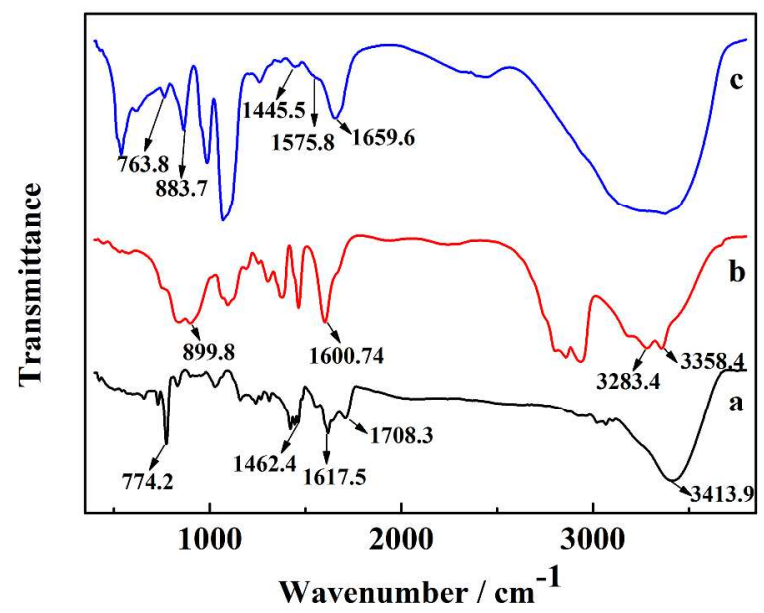

Figure S1. FTIR spectra of $\mathrm{Ru}(\mathrm{bpy})_{2}(\mathrm{mcbpy})^{2+}$ (curve a), TAPA (curve b), and $\mathrm{Ru}(\mathrm{bpy})_{2}(\mathrm{mcbpy})^{2+}$-TAPA (curve c).

\section{UV-vis absorption spectroscopy characterization of different complexs}

In addition, UV-vis absorption spectroscopy was applied to demonstrate the structure of $\mathrm{Ru}(\mathrm{bpy})_{2}(\mathrm{mcbpy})^{2+}-\mathrm{TAPA}$, and the results were displayed in Figure S2. Three strong absorption peaks at $245 \mathrm{~nm}, 285 \mathrm{~nm}$, and $455 \mathrm{~nm}$ were observed in $\mathrm{Ru}(\mathrm{bpy})_{2}(\mathrm{mcbpy})^{2+}$ solution, which belonged to the characteristic $\pi \rightarrow \pi^{*}$ transition for $\mathrm{C}=\mathrm{C}$ and the $\mathrm{n} \rightarrow \pi^{*}$ transition for $\mathrm{C}=\mathrm{N}$ (curve a). Moreover, $\mathrm{Ru}(\mathrm{bpy})_{2}(\mathrm{mcbpy})^{2+}$ had absorption peak at $207 \mathrm{~nm}$ due to the $\pi \rightarrow \pi^{*}$ transition for $\mathrm{C}=\mathrm{O}$ in carboxylic acid groups. In the $\mathrm{UV}$-vis absorption spectroscopy of TAPA (curve b), the peak at $228 \mathrm{~nm}$ was ascribed to $\mathrm{n} \rightarrow \sigma^{*}$ transition for $-\mathrm{NH}_{2}$. When TAPA was cross-linked onto $\mathrm{Ru}(\mathrm{bpy})_{2}(\mathrm{mcbpy})^{2+}$, the characteristic peak of $\mathrm{n} \rightarrow \pi^{*}$ transition for $\mathrm{C}=\mathrm{O}$ in amide bond at $217 \mathrm{~nm}$ was obviously observed, indicating the successful amidation reaction. At the same time, after the formation of $\mathrm{Ru}(\mathrm{bpy})_{2}(\mathrm{mcbpy})^{2+}$-TAPA, the absorption peaks at $245 \mathrm{~nm}$, $285 \mathrm{~nm}$, and $455 \mathrm{~nm}$ shifted to $241 \mathrm{~nm}, 282 \mathrm{~nm}$ and $453 \mathrm{~nm}$, respectively. According to the UVvis absorption spectroscopy, we could also conform that the Ru(bpy $)_{2}(\text { mcbpy })^{2+}$-TAPA complex was prepared successfully. 


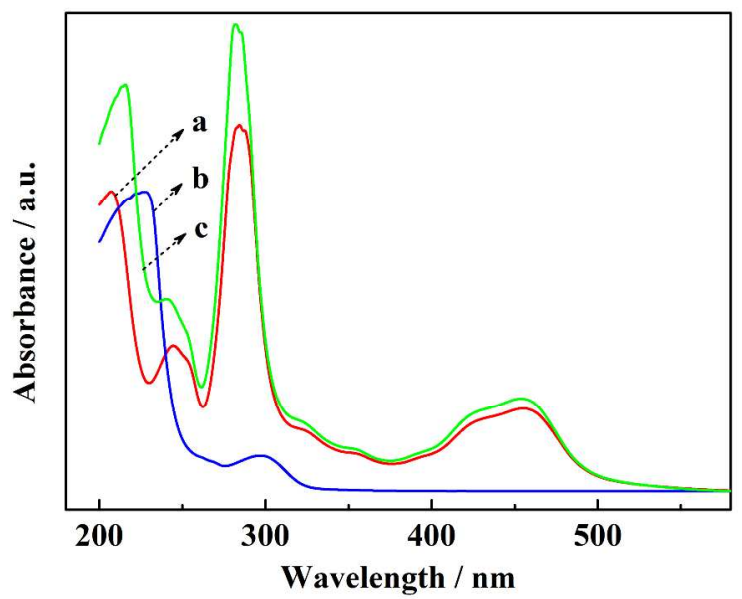

Figure S2. UV-vis absorption spectroscopy of $\mathrm{Ru}(\mathrm{bpy})_{2}(\mathrm{mcbpy})^{2+}$ (curve a), TAPA (curve b), and $\mathrm{Ru}(\mathrm{bpy})_{2}(\mathrm{mcbpy})^{2+}-\mathrm{TAPA}($ curve c). 